\title{
Analysis on the Changes of China's National Income and Consumption Structure
}

\author{
Jingwen $\mathrm{Xu}^{1, *}$ \\ International Division of Beijng No. 2 Middle School, Beijing, China, 100010 \\ *Corresponding author. Email: XJINGWEN2021@126.com
}

\begin{abstract}
With the rapid economic development in China, Chinese people have experienced long-term wealth accumulation. The new generation born after 2000 has great consumption potential. Moreover, for China's future economic development, consumption is very important. In addition to drive China's own economic development, it will also unite relevant countries to build a community of common destiny. Therefore, this paper aims to find a set of marketing solutions that can be accepted by the new generation. Through the analysis of historical data, this paper analyses the different marketing schemes adopted in the process of China's wealth accumulation due to the calculation development restrictions at different ends of the year and people's preferences at that time. By analysing the completely different information receiving methods brought by modern technology to the new generation and their impact. It also analyzes the reasons for the generation of marketing schemes such as fan economy and live broadcasting with goods in contemporary marketing schemes. Through analysis, it is believed that the new generation has more direct and extensive access to information based on new technologies. Although it seems that the new generation should pursue themselves more, they should reduce the cost of information acquisition and group communication through new technologies. On the contrary, the new generation is more affected by herding. Therefore, companies need to pay more attention to network traffic, network popularity effect and firmly grasp the consumption psychology of the new generation when making the new marketing plans.
\end{abstract}

Keywords: consumption structure, marketing strategy, savings rate, Internet, fans economics

\section{INTRODUCTION}

After decades of rapid economic development, China's national wealth has accumulated rapidly. The Chinese have maintained the world's highest savings rate for many years. China has great consumption potential. However, consumption has been at the lowest level in the world for a long time. How to release this huge consumption potential? For the new generation born after 2000 , what marketing strategies are effective for them? The author consulted relevant materials on the Internet and found that there are few studies in this field. Therefore, the author analyses the changes of marketing strategy from the changes of China's national income, consumption structure and population structure, so as to find an effective marketing strategy for the new generation born after 2000 in China.

For the new generation born in China after 2000, they will inherit the huge wealth accumulated by the rapid development since the founding of new China and will soon become the main consumer in China in the future. Compared with their parents and grandparents, they have accumulated huge wealth and stand in the new era of highly developed science and technology. How do they view consumption? What are they interested in? What are the most effective marketing methods for them?

This paper mainly collects the historical data of China's economy, and analyses the accumulation of wealth, the change of population structure, the accumulation of wealth and some hot events of the new generation of consumption cases. It shows that the best-selling consumer products, marketing methods and marketing media are completely different in different years, so as to analyses and obtain a set of effective marketing strategies for the new generation.

China has become the second largest economy in the world. It has become a world factory and one of the main suppliers of consumer goods in the world. However, for the future development of China's 
economy, only manufacturing and production is not enough. If China's consumption cannot be started, it will limit China's future economic development. If compared with the consumption in the United States, the world's largest economy, the United States can not only provide the creation of advanced scientific and technological products, but also the largest consumer. Relatively speaking, the U.S. economy is more closely tied to the economies of all countries in the world. This is more conducive to the voice of the United States in the economic field. Therefore, in order to bring China's future economy to a higher level, China needs to solve the problem of consumption and further improve the quality of national life. While consuming, it will also create more economic opportunities for China and other countries. This paper aims to find an effective marketing strategy for the new generation born in China after 2000. This will help China improve its comprehensive strength and balance international relations. It is more conducive to the common development and common progress of the majority of countries through global trade.

\section{ANALYSIS OF THE CHANGES}

\subsection{Wealth accumulation}

Since the founding of the people's Republic of China, from poverty and weakness to reform and opening, China has joined the WTO and developed into a world factory. According to Figure 1, IMF GDP data of countries in 2010-2021, since 2010, China's GDP has surpassed Japan and jumped to the second largest economy in the world. And, from 2010 to 2021, the major country such as Japan, Germany, France, United Kingdom, India, Brazil, Italy, Russia, etc, their GDP keep flat or dropped a little bit. But only United States and China keep growth rapidly.

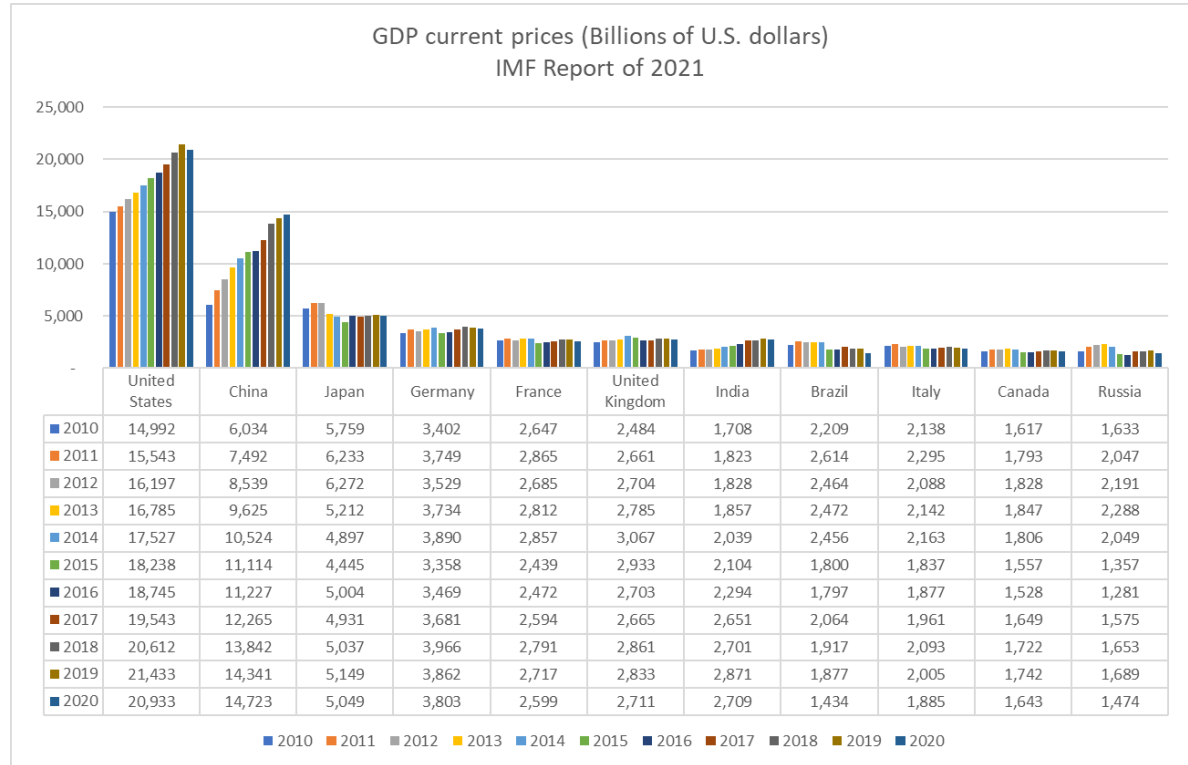

Figure 1 IMF GDP data of countries in 2010-2021 (USD) [1]

However, China is still the most populous country in the world. There is still a huge gap between Chinas' per capita gross national income and high-income countries. But, China's per capita national income is growing very fast.

According to Figure 2, GNI Per Capita, the data source is provided by World Bank WDI Database, by 2017, China's per capita GNI was finally higher than that of upper middle-income countries. Although, there is still a huge gap between Chinas' per capita gross national income and high-income countries. However, according to the World Bank WDI data, in terms of growth rate, China's per capita national income is growing very fast. Comparing the data of 2017 and 2000 , we can see that China's growth rate is $824.5 \%$. The growth of world per capita national income was $89.3 \%$. Per capita growth in high-income countries was $59.4 \%$. The rapid growth of income has laid the foundation for Chinese people's consumption. 
Table 1. GNI Per Capita (USD) [2]

\begin{tabular}{|l|l|l|l|l|l|l|}
\hline \multicolumn{7}{|c|}{ GNI Per Capita } \\
\hline Country or Area & 2000 & 2005 & 2010 & 2015 & 2016 & 2017 \\
\hline World & 5475 & 7337 & 9380 & 10595 & 10326 & 10366 \\
\hline High Income & 25184 & 33629 & 38621 & 40925 & 40009 & 40136 \\
\hline Middle Income & 1167 & 1825 & 3585 & 4958 & 4860 & 4940 \\
\hline Lower Middle Income & 537 & 830 & 1505 & 2047 & 2062 & 2118 \\
\hline Upper Middle Income & 1801 & 2874 & 5870 & 8272 & 8063 & 8192 \\
\hline Low and Middle Income & 1083 & 1680 & 3267 & 4482 & 4385 & 4451 \\
\hline Low Income & 267 & 365 & 611 & 762 & 734 & 744 \\
\hline Least Developed Countries & 283 & 406 & 742 & 961 & 954 & 990 \\
\hline Heavily Indebted Poor Countries & 302 & 416 & 710 & 874 & 862 & 879 \\
\hline China & 940 & 1760 & 4340 & 7950 & 8250 & 8690 \\
\hline
\end{tabular}

\subsection{Low consumption}

The Chinese wallet is bulging. Did the consumption rate of Chinese residents rise sharply? Let's look at the relevant data. Reference data of World Bank WDI Database, In Figure 3, We can see the historical data. Compare with some major countries, from 2000 to 2018, China's household final consumption rate is always lower than that of other countries.

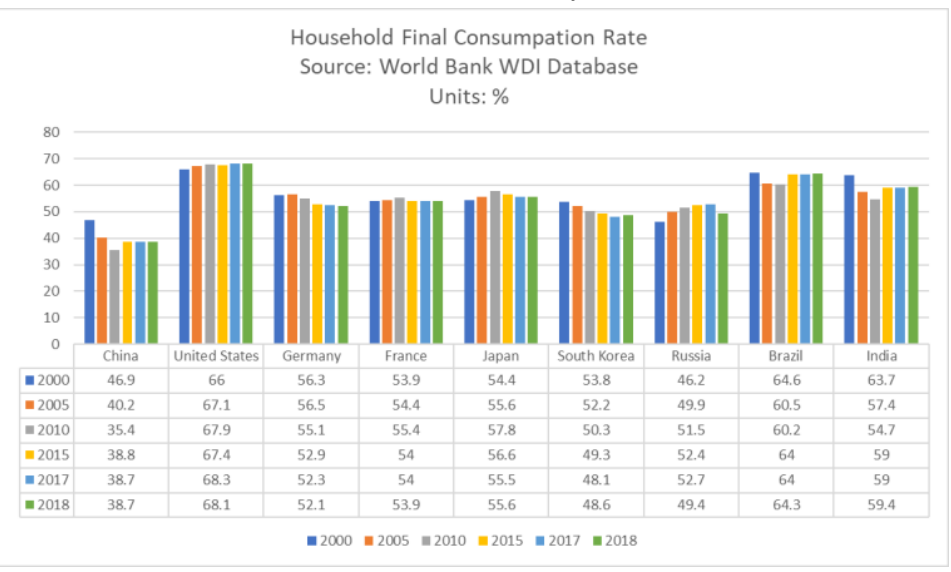

Figure 3 Household Final Consumption Rate [3]

\subsection{Savings rate}

Let's look at China's savings rate [4]. In ChinaIRN web site, we can get a report that Liu Mingyue published in Nov 12, 2019. In the report, Liu Mingyue record the number of savings rates of China that provide by Mr. Zhou Xiaochuan, President of China Financial Society and former president of the people's Bank of China. In Annual meeting of Finance and Economics that hold in Nov 12, 2019, Mr. Zhou Xiaochuan said that China's savings rate is more than $50 \%$ in last 10 years. In 2019 , the China's saving rate is $45 \%$. It still is the No1 savings rate in the world.

Based on the above historical data, we can see a clear picture. China's overall economy has taken off rapidly, and China's resident income has increased significantly. However, China's savings rate still ranks No1 in the world, and the consumption of Chinese residents still has a lot of room for development. In other words, after years of wealth accumulation, the consumption potential of Chinese residents is huge.

\section{THE CHANGES IN CHINA'S CONSUMER MARKET}

Referred to the article that Yifu Fu published on the website in Dec 18, 2018, the changes in China's consumer market can be seen clearly [5].

First, at the beginning of the founding of new China, China was in a state of waiting for prosperity, and China's national and national income was relatively low. Before the reform and opening in 1978, China's economy was a planned economic system, and the development of social productive forces was limited. The national income is distributed according to the planned economic system, and the national income is generally not high. Under the planned economic system, there is no personalized consumption system at all. 
More importantly, at that time, China was still in a difficult stage of solving the problem of food and clothing. These factors have led to the inhibition of consumption. After the reform and opening, the economic system reform represented by the household contract responsibility system has fundamentally liberated the rural productive forces. The first problem to be solved is the problem of food and clothing. During this period, food consumption showed a sharp upward trend. Residents' consumption is gradually released through food consumption. After 1985, the light industry represented by textile and food processing ushered in a development opportunity. Based on solving the basic problem of food and clothing, the consumption of durable consumer goods began to rise. At that time, representative products were called "old three pieces". Bicycles, watches and sewing machines. With the further development of productivity, consumption gradually turns to the "new three": TV, refrigerator and washing machine. By 1992, China had started the reform of its economic system. Productivity has increased significantly. At the same time, China has entered the high-speed development channel of reform and opening. Moreover, in 2001, China finally joined the WTO. Economic construction began to be in line with international standards. New electrical equipment is constantly emerging. Fixed line telephones, air conditioners, computers, mobile phones, microwave ovens, cameras and other electronic consumer goods have gradually become the main force of people's consumption. At the same time, the consumption of transportation, culture, education, and entertainment has gradually grown from scratch, and then increased rapidly. In 1998, the Asian financial crisis occurred. The Chinese government adjusted its strategic decision to stimulate economic growth by expanding domestic demand. During this period, China's national consumption was mainly upgraded through housing and transportation consumption and service consumption. In July 1998, the State Council issued the notice on further deepening the reform of urban housing system and accelerating housing construction, marking a new era of housing marketization and monetization of housing consumption in China from the previous housing distribution system of planned economy. Housing purchase has become the largest consumption category of residents' consumption. At the same time, with the upgrading of consumption, automobile consumption gradually rises. The marketization of housing has expanded the space of "living", and the automobile has expanded the space of "traveling". At the same time, consumer spending in cultural, educational, entertainment, medical insurance and other service areas has also increased rapidly. In addition, with the reform and opening, some people get rich first. At the same time, after China's entry into WTO, the economy is gradually in line with the world, and the consumption of luxury goods is gradually rising. In 2004, China's luxury consumption accounted for $12 \%$ of the global market share. By 2017, this figure had increased to $22.1 \%$. It has become the second largest luxury consumer market in the world after the United States.

Since 2008, with the rapid development and application of Internet technology. E-commerce mode began to rise and spread at a super high speed, and people's consumption habits and consumption patterns have undergone fundamental changes. Online shopping has become the first choice for everyone. Mobile app has become a platform for personal shopping, communication, entertainment, travel and so on. To adapt to this development trend, manufacturing and retail industries put forward the concept of new production mode and "new retail". China's overall consumption, production and retail model has undergone fundamental changes.

The change of income, the upgrading of consumption mode, the change of population structure, the change of economic structure and other factors will affect people's choice of consumer goods. Different marketing strategies should be considered in different periods.

\section{CHANGES IN POPULATION STRUCTURE}

Figure 4 shows the birth rate, death rate and natural growth rate in the web site of national bureau of statistics of China. It is clear, the birth rate keep drop and death rate keep flat. The natural growth rate drops rapidly. 


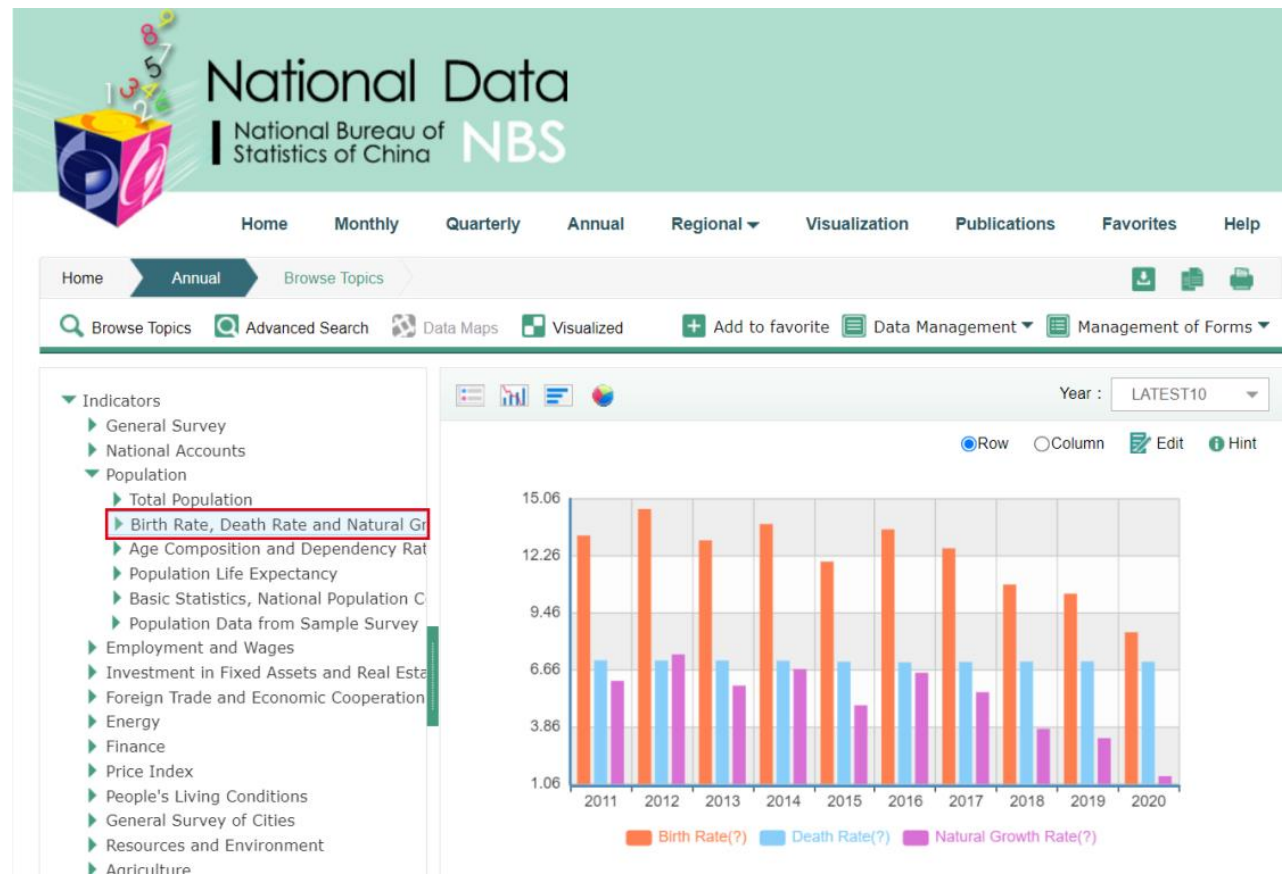

Figure 4 Birth Rate, Death Rate and Natural Growth Rate of China from 2011 to 2020 [6]

Figure 5 is the screenshot form the web site of bureau of statistics of China. In Figure 5, we can see the report of the age composition information. The total population keep growth. But, according to the information in Figure 4, the natural growth rate drops significantly. That is mean, the total population will drop in the future.

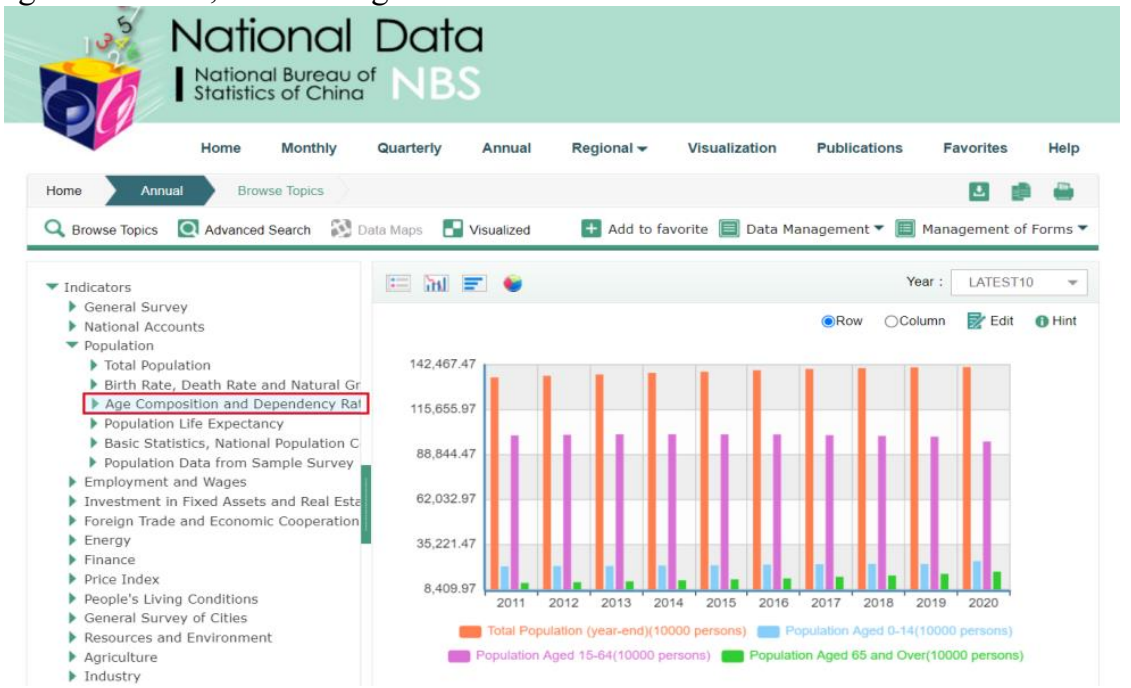

Figure 5 Birth Rate, Death Rate and Natural Growth Rate of China from 2011 to 2020 [7]

In Figure 5, we can see the population of age 0-14 keeps flat. The population of age 65 and over keep growth. The population of age 15-64 start to drop from 2020.

The number tell us that China's population structure is a funnel-shaped structure. Combination the No.1 saving rate in past year that we showed before. That is mean, the new generation born after 2000 will Inherit a lot of wealth. When they enter the main group of
Chinese consumption, China's consumer market will explode.

\section{FUTURE CONSUMPTION CHANNELS}

With the development of science and technology and the rapid popularization of mobile Internet technology and mobile Internet applications, China's consumption channels have quickly switched to the e-commerce model based on mobile Internet technology. 


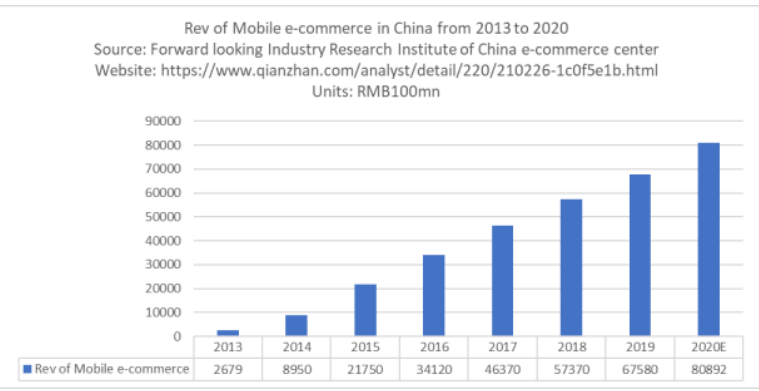

Figure 6 Rev of Mobile e-commerce in China from 2013 to 2020 [8]

In Figure 6, we can see the rev of mobile e-commerce in China grow very fast from 2013 to 2020. The data source is the report of Cai yuqing's "Analysis on market status and development trend of China's mobile e-commerce industry in 2021" in Forward the Economist web site in Feb 26, 2021.

And in the report of Cai yuqing's "Analysis on market status and development trend of China's mobile e-commerce industry in 2021 ", we also can find the data in Figure 7. We can see the user number that use mobile for online shopping and the usage rate of mobile online shopping application. That is mean, the major consumer channel had been changed to online shopping through mobile application in China. And if we make marketing strategy for new generation after 2000. We have to use a new market methodology that should focus on mobile applications.

\section{PROSPECT OF THE NEW GENERATION OF THE MILLENNIUM AND THE FUTURE CONSUMPTION TREND}

First, in terms of population structure, China has finally fundamentally changed its population structure after long-term implementation of family planning. The new generation born after 2000 will become a funnel-shaped structure and will eventually bear the pressure and wealth. The rapid accumulation of wealth of previous generations will be passed on to the new generation after 2000. The new generation has been in the era of China's national strength taking off since its birth. They have not experienced the poverty in the early days of the founding of the people's Republic of China, and they will not have to experience the high pressure of housing consumption. The reason is that the population structure leads the new generation to inherit many heritages left by their grandparents. When the new generation becomes the main consumer, their concerns, their consumption patterns, and their needs will become the key issues to be considered in the new marketing strategy. For example, luxury consumption should have a broader space. How to locate luxury goods that are more in line with the appetite of the new generation. For

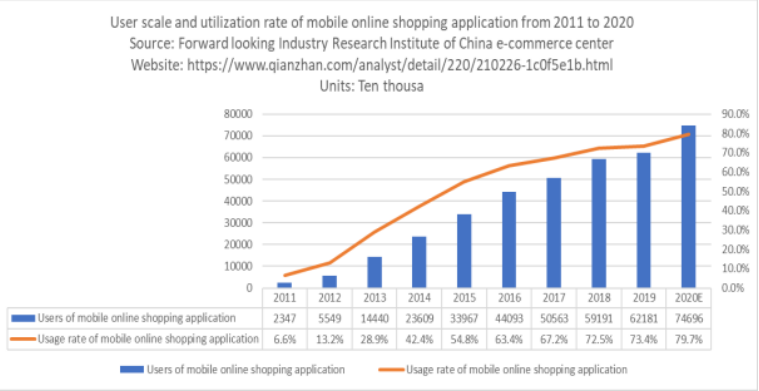

Figure 7 Uses and utilization rate of mobile online shopping in China from 2011 to 2020 [9]

example, fan economy, using the control of public opinion to achieve marketing purposes, and so on. Will become a problem that needs to be considered in the future marketing strategy.

So, if we want to win the customer from the new generation born after 2000, we have to understand the economic development history in China and we need fully understand consumer psychology of the new generation born after 2000 .

\section{CONCLUSION}

The new generation has great consumption potential. Moreover, their access to information, with the help of the mobile Internet, has been far different from their parents. Therefore, only new marketing methods can meet the consumer needs of the new generation. Due to the high-speed dissemination of information and the wide popularization of new mobile network applications, the new generation is more vulnerable to public opinion than their parents. The new generation is a complex of contradictions. They pursue individuality. However, through the transmission of mobile network information, they are eager to be recognized. Under the guidance of public opinion, herding is more obvious than their parents. It is for these reasons that the new generation has a more herd mentality. Therefore, like the fan economy, live broadcasting with goods can be popular today. Therefore, the new marketing method needs to establish a brand image in the new generation of groups through traffic channels and online popularity. Seize the heart of the new generation.

In China's future economic construction, consumption will become an important magnetic force to condense the economic circle. With the release of China's consumption power, more and more countries will be absorbed into the huge magnet of China's consumption, turning everyone into a closely integrated community of destiny. This will greatly change China's position in the world economy. From today's world factory to the core of the community of common destiny. Therefore, China will be more and more needed by the world. Based on this, the establishment of a new marketing system in line with the new generation is very 
important for the future development of China's economy.

\section{AUTHORS' CONTRIBUTIONS} $\mathrm{Xu}$

This paper is independently completed by Jingwen

\section{ACKNOWLEDGMENTS}

Thank you very much for your training and guidance. This study and thesis writing can be said to help me open the door of the palace of economic theory analysis based on learning the basic knowledge of economics in school. Let me see the charm of economic theoretical analysis. It can be said that this study has strengthened my determination to choose the road of economics in the future. Thank my economics teacher Miss Zhang and my BC teacher Miss Yu. They gave me a lot of guidance on how to write this paper, so that I can complete this study and thesis writing.

\section{REFERENCES}

[1] IMF GDP data of countries in 2010-2021 (Billions of U.S. dollars) https://www.imf.org/external/datamapper/NGDPD @WEO/OEMDC/ADVEC/WEOWORLD

[2] GNI Per Capita of World Bank WDI Database (USD) https://www.docin.com/p-840946342.html

[3] Household Final Consumption Rate of World Bank WDI Database (\%) https://wenku.baidu.com/view/c016f24e7175a4178 66fb84ae45c3b3567ecddd2.html

[4] Liu Mingyue's report, "Data of China's savings rate over the years", by ChinaIRN, Nov 12, 2019. https://www.chinairn.com/hyzx/20191112/1706195 97.shtml

[5] Fu Yifu, "Changes of China's consumer market in the 40 years of reform and opening up" in Opinion.jrj.com web site in Dec 18, 2018. http://opinion.jrj.com.cn/2018/12/18152626759619 .shtml

[6] Birth Rate, Death Rate and Natural Growth Rate of China from 2011 to 2020. Data source: National Bureau of Statistics of China.

Web site: https://data.stats.gov.cn/english/easyquery.htm?cn $=\mathrm{C} 01$

[7] Age Composition of China from 2011 to 2020. Data source: National Bureau of Statistics of China. https://data.stats.gov.cn/english/easyquery.htm?cn= $\mathrm{C} 01$
[8] Cai yuqing, Report "Analysis on market status and development trend of China's mobile e-commerce industry in 2021" in Forward the Economist web site in Feb 26, 2021.https://www.qianzhan.com/analyst/detail/220/ 210226-1c0f5e1b.html

[9] Cai yuqing, Report "Analysis on market status and development trend of China's mobile e-commerce industry in 2021" in Forward the Economist web site in Feb 26, 2021. https://www.qianzhan.com/analyst/detail/220/2102 26-1c0f5e1b.html 